\title{
Mechanistic Aspects of Vanadium-Catalysed Oxygen Transfer Reactions
}

\author{
Christian Klarner Sams and Karl Anker Jørgensen ${ }^{\dagger}$ \\ Department of Chemistry, Aarhus University, DK-8000 Aarhus C, Denmark
}

\begin{abstract}
Sams, C. K. and Jørgensen, K. A., 1995. Mechanistic Aspects of VanadiumCatalysed Oxygen Transfer Reactions. - Acta Chem. Scand. 49: 839-847 (c) Acta Chemica Scandinavica 1995.

Vanadium-catalysed oxidations in organic media have been investigated using mainly tert-butyl hydroperoxide, TBHP, as the terminal oxidant and vanadyl(IV) acetylacetonate, OV(IV)(acac), vanadyl(IV) benzoylcamphorate, OV(IV)(camp), or vanadyl(IV) $5,10,15,20$-tetraphenylporphyrin, OV(tpp), as the catalysts. Kinetic studies of the initial reaction between OV(IV)(acac) and TBHP were performed using EPR and UV spectroscopy. The experimental data suggest a second-order reaction, first order in OV(IV)(acac) $)_{2}$ and in TBHP. IR spectroscopic studies of the reaction show that the $\mathrm{V}=\mathrm{O}$ functionality is intact after the oxidation has taken place and, furthermore, UV, IR and ${ }^{1} \mathrm{H}$ NMR spectroscopic investigations all indicate that the acetylacetonate ligands remain bound to the vanadium atom during the oxidation of $\mathrm{OV}(\mathrm{IV})(\mathrm{acac})_{2}$ to a $\mathrm{OV}(\mathrm{V})(\mathrm{acac})_{2}$ complex. The oxidation of the vanadium(IV)- to the vanadium(V)-complexes is very dependent on the organic ligand attached to the metal. Studies of the oxidation of thianthrene 5oxide using different vanadium catalysts and TBHP as the terminal oxidant show that the electronic nature of the transferred oxygen atom is electrophilic. The initial oxygen-transfer step in the epoxidation of $(Z)$-stilbene is proposed to be a reversible process that occurs via a non-concerted pathway. The vanadiumcatalysed oxidation of conjugated dienes has also been discussed and the results are discussed in relation to the oxidation taking place on a vanadyl pyrophosphate surface.
\end{abstract}

Vanadium systems can catalyse a variety of different oxidation reactions. ${ }^{1,2}$ Simple vanadium complexes can catalyse the oxidation of different organic compounds, ${ }^{3}$ and more complex vanadium systems such as enzymes ${ }^{4,5}$ and surfaces $^{6-8}$ also show catalytic properties.

Discrete vanadium complexes can catalyse the epoxidation of alkenes by hydrogen peroxide or tert-butyl hydroperoxide (TBHP) as the terminal oxidant, ${ }^{9-14}$ as well as catalyse the direct hydroxylation of aromatics and alkanes. ${ }^{15}$ The reactive intermediates in these oxidation reactions are suggested to be vanadium-peroxo complexes, 1 , or vanadium-peroxide complexes, $2,{ }^{16,17}$ some of which have been characterised by X-ray structure determination. ${ }^{16-19}$

Oxygen transfer to an alkene from 1 or $\mathbf{2}$ takes place in a non-stereoselective manner as the epoxidation of $\mathrm{cis}$ alkenes leads to a mixture of cis- and trans-epoxides. ${ }^{16,17}$ The non-stereospecific oxygen transfer is probably associated with the relatively facile reducibility of the vana$\operatorname{dium}(\mathrm{V})$ centres and it has been suggested that the vanadium(IV)-peroxo-alkene radical or vanadium(IV)

\footnotetext{
$\lceil$ To whom correspondence should be addressed.
}<smiles>O1O[Al]1</smiles>

1<smiles></smiles>

2 peroxide alkene radical, 3 or $\mathbf{4}$, respectively, is involved in the oxygen-transfer step to the alkene. ${ }^{16,17}$ It is notable that the proposed radical nature of the intermediate is in sharp contrast with the related vanadium(V) catalysed stereoselective epoxidation of allylic alcohols. ${ }^{20}$ However, it should be noted that some controversy has arisen concerning the nature of the reactive intermediate in these oxygen transfer reactions. ${ }^{15}$

Several vanadium complexes can catalyse the epoxidation of alkenes, and among the simpler complexes is vanadyl(IV) acetylacetonate, $\left[\mathrm{OV}(\mathrm{IV})(\mathrm{acac})_{2}\right], 5$, which, especially, has been used for the epoxidation of allylic alcohols with TBHP as the terminal oxidant. ${ }^{20}$ For the vanadium(IV) complexes such as $\mathbf{5}$, the active catalyst is probably not a species with the metal atom in oxidation 


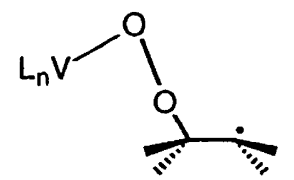

3

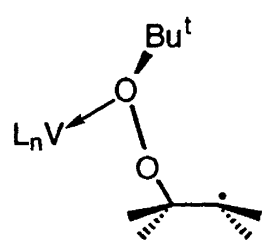

4 state IV and it has been proposed that the vanadium atom has oxidation state $\mathrm{V}$ in the active catalyst. ${ }^{20}$

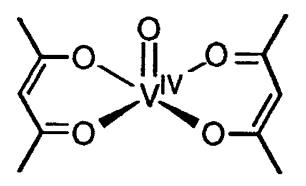

5

Moving from the discrete vanadium complexes to vanadium surfaces it has been found that the vanadyl pyrophosphate surface (VPS) can catalyse the oxidation of butane to maleic anhydride using $\mathrm{O}_{2}$ as the terminal oxidant [eqn. (1)]. ${ }^{6}$ The oxidation of butane to maleic anhydride is important from both an academic and an industrial point of view as maleic anhydride is produced industrially this way.

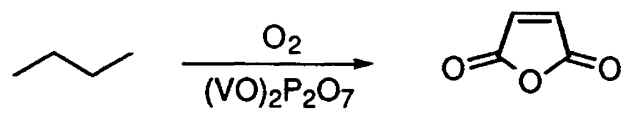

One of the crucial steps in the oxidation of butane to maleic anhydride on a VPS is the formation of 2,5-dihydrofuran from 1,3-butadiene. ${ }^{6}$ It has been postulated from both an experimental ${ }^{6}$ and a theoretical ${ }^{7}$ point of view that this oxidation takes place by an 1,4-addition to 1,3-butadiene of an electrophilic oxygen atom bound to a vanadium atom on the surface, 6 . The 1,4-addition of atomic oxygen atom to 1,3-butadiene is not a unique reaction for VPS, atomic oxygen adsorbed on a $\operatorname{Ag}(110)$ surface reacts with 1,3-butadiene to give a similar reaction, ${ }^{21}$ but the mechanism for the formation of 2,5-dihydrofuran on the $\operatorname{Ag}(110)$ surface is probably different from the mechanism on the VPS. ${ }^{22}$

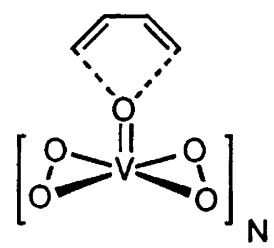

6
If one compares the epoxidation of alkenes catalysed by discrete vanadium complexes with the oxidation of butane to maleic anhydride catalysed by the VPS, the first reaction probably takes place on the oxovanadium peroxo/peroxide intermediate, whereas an oxovanadium complex is probably the reactive intermediate of the latter.

The purpose of this paper is to present a mechanistic investigation of vanadium-catalysed oxidation reactions related both to epoxidation reactions catalysed by discrete vanadium complexes, and to oxidations catalysed by the VPS, i.e., to determine whether there is a difference in the reaction pattern for the oxidation of alkenes relative to 1,3-dienes. Attempts will be made to answer the following questions. ( $i$ ) What is the nature of the active catalyst and how is the active catalyst formed from the discrete vanadium complexes? (ii) What are the electronic properties of the oxygen atom that is transferred to the alkene, is it electrophilic, nucleophilic, a radical or a nonradical? (iii) Can discrete vanadium complexes catalyse reactions similar to those taking place on a VPS?

\section{Results and discussion}

I. IR, EPR and UV spectroscopic studies of the oxidation of $\mathrm{OV}(\mathrm{IV})(\mathrm{acac})_{2}$. The stoichiometric reaction of 5 with TBHP was studied by IR spectroscopy. Complex 5 in $\mathrm{Cl}\left(\mathrm{CH}_{2}\right)_{2} \mathrm{Cl}$ showed an absorption band at $1002.27 \mathrm{~cm}^{-1}$, which was assigned to the $\mathrm{V}=\mathrm{O}$ stretch. The addition of TBHP at room temperature (rt) resulted in the rapid formation of a broad peak $994.07 \mathrm{~cm}^{-1}$, which then slowly disappeared with concurrent formation of a sharp peak at $1002.75 \mathrm{~cm}^{-1}$. These results indicated that the $\mathrm{OV}(\mathrm{V})(\mathrm{acac})_{2}$ complex still has a $\mathrm{V}=\mathrm{O}$ bond.

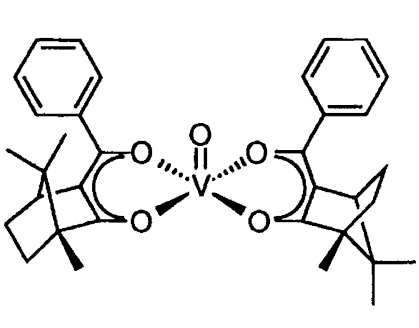

7

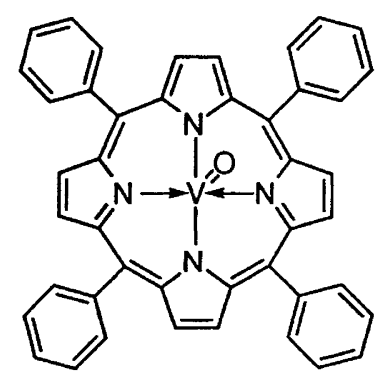

8
The oxidation of $\mathrm{OV}(\mathrm{IV})(\mathrm{acac})_{2}, 5, \mathrm{OV}(\mathrm{IV})(\mathrm{camp})_{2}, 7^{23}$ and $\mathrm{OV}(\mathrm{IV})(\mathrm{tpp}), \mathbf{8}$, by TBHP was investigated using EPR spectroscopy. The complexes 5, 7 and $\mathbf{8}$ are stable $\mathrm{d}^{1}$ metal systems and are EPR active. The EPR spectrum of 5 in $\mathrm{CH}_{2} \mathrm{Cl}_{2}$ at $\mathrm{rt}$ is shown in Fig. 1 .

The EPR spectrum of $\mathbf{5}$, as well as of $\mathbf{7}$ and $\mathbf{8}$ showed the expected splitting of an unpaired electron coupled to a nucleus of $S=7 / 2$. For 5 the hyperfine splitting was measured to be $95.8 \mathrm{G}$, while complex 7 and 8 had hy- 


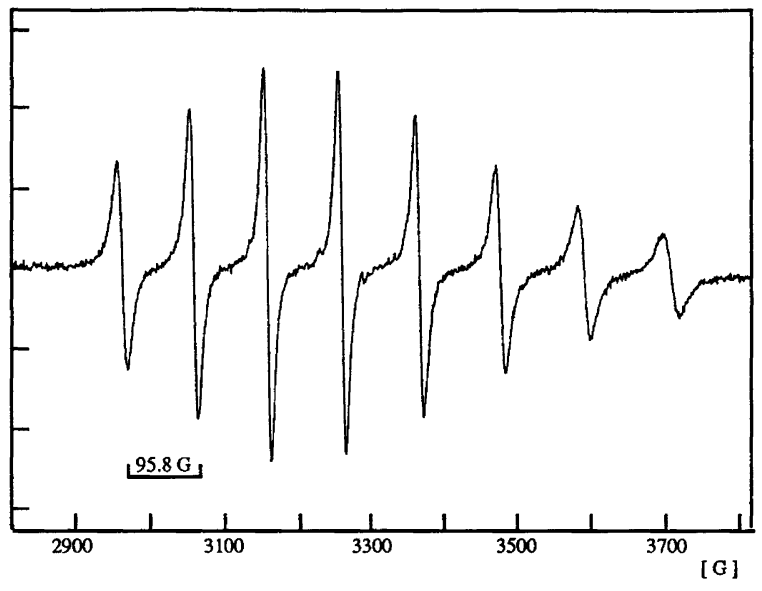

Fig. 1. The EPR spectrum of $\mathrm{OV}(\mathrm{IV})(\mathrm{acac})_{2}$ in $\mathrm{CH}_{2} \mathrm{Cl}_{2}$.

perfine splitting of $97.0 \mathrm{G}$ and $86.2 \mathrm{G}$, respectively. When 5 and 7 were oxidised by TBHP the signals in the EPR spectrum disappeared rapidly while 8 was oxidised much more reluctantly. Complex 8 required a large excess of TBHP to be oxidised. Furthermore, 8 was apparently not oxidised by iodosylbenzene (PhIO) as 5 and 7 . In an attempt to account for the resistance of the latter to be oxidised by TBHP and PhIO the electrochemical oxidation of 5 and $\mathbf{8}$ was performed. The oxidation potential of 5 was measured to be $1.3 \mathrm{~V}$ (in DMF vs. $\mathrm{Ag} / \mathrm{AgI}$ ), while that of 8 was larger than $2.1 \mathrm{~V}$, supporting the different oxidation behaviour observed by EPR spectroscopy. Quantum chemical calculations using the INDO/ $1^{24-27}$ procedure gave singly occupied molecular orbital energies for 5 and 8 of $-7.6 \mathrm{eV}$ and $-8.5 \mathrm{eV}$, respec- tively. The EPR, electrochemical and theoretical results indicated thus that the ligand attached to the vanadium atom is of the utmost importance to the electronic environment at the metal. It should be noted that in a related series of oxo-molybdenum-peroxo complexes both the reduction potentials and $v_{\mathrm{O}-\mathrm{O}}$ were recently found to be sensitive to the organic ligand attached to the metal. $^{28}$

Based on the total disappearance of the EPR signal of 5 the stoichiometry of the oxidation was determined as that shown in eqn. (2),

$$
\underset{5}{2 \mathrm{OV}(\mathrm{IV})(\mathrm{acac})_{2}}+\left(\mathrm{CH}_{3}\right)_{3} \mathrm{COOH} \rightarrow 2 \mathrm{OV}(\mathrm{V})(\mathrm{acac})_{2} \mathrm{X}
$$

where $\mathrm{X}$ is a ligand, probably attached to the vanadium atom (vide infra).

We have investigated the kinetics of the disappearance of the centre line in the EPR spectrum of 5 under the following reaction conditions: [5] $=0.67 \mathrm{mM}$ and [TBHP] $=0.33 \mathrm{mM}$ at $20^{\circ} \mathrm{C}$. The rate expression for the secondorder reaction where the reactants are present in stoichiometric ratios is given in eqn. (3).

rate $=\frac{1}{2} \frac{\mathrm{d}\left[\mathrm{OV}(\mathrm{acac})_{2}\right]}{\mathrm{d} t}=-k\left[\mathrm{OV}(\mathrm{acac})_{2}\right][\mathrm{TBHP}]$

The solution to this equation is eqn. (4).

$\left[\mathrm{OV}(\mathrm{acac})_{2}\right]_{t}=\frac{1}{\left[\mathrm{OV}(\mathrm{acac})_{2}\right]_{0}^{-1}+k t}$

Fig. 2 shows the decay of the EPR signal of 5 as a function of time, together with the least-squares fit of the

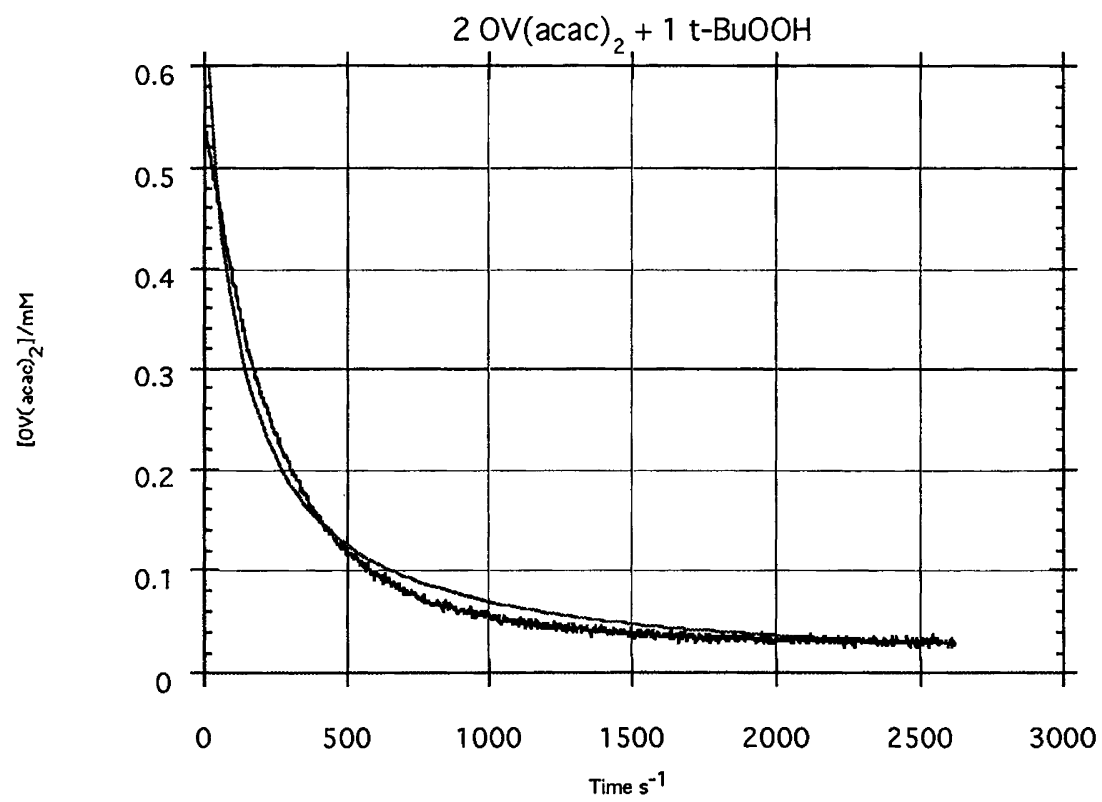

Fig. 2. The decay of the EPR signal (centre line) of OV(IV) (acac) $)_{2}$ as a function of time in the reaction with TBHP. The 'unperturbed' line is the least-squares fit. 


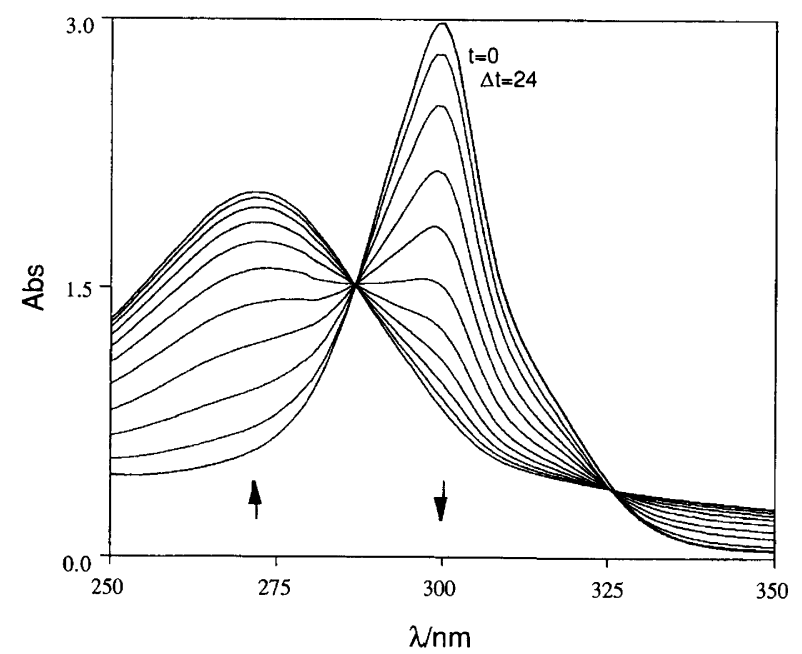

Fig. 3. The change in the UV spectrum of $O V(I V)(a c a c)_{2}$ by reaction with TBHP as a function of time.

function according to eqn. (4). The second-order rate equation proved to be the best integral order model with a correlation coefficient of 0.991 . The rate constant $k$ was calculated to be $12.9 \mathrm{M}^{-1} \mathrm{~s}^{-1}$.

The reaction of 5 and TBHP in $\mathrm{Cl}\left(\mathrm{CH}_{2}\right)_{2} \mathrm{Cl}$ at $\mathrm{rt}$ was also been investigated by UV spectroscopy using $0.16 \mathrm{mM}$ concentrations for both reagents. The change in the UV spectrum for the reaction of 5 with TBHP as a function of time is shown in Fig. 3.

Complex 5 absorbed at $300 \mathrm{~nm}$, but this absorbance decreased when 5 was oxidised, and a new absorbance appeared at $272 \mathrm{~nm}$. The intensity of the absorbance at $300 \mathrm{~nm}$ was measured over a period of $30 \mathrm{~min}$ and the concentration of 5 fitted the same rate laws as found by the EPR experiments. The rate constant for the disappearance of $\mathbf{5}$ in the UV experiment was calculated to be $12.5 \mathrm{M}^{-1} \mathrm{~s}^{-1}$, which is very similar to the value obtained by the EPR experiments.

The UV experiments of the reaction of 5 with TBHP showed the formation of a complex which was apparently stable in solution as the absorbance at $272 \mathrm{~cm}^{-1}$ was constant for several hours. The reaction of 5 with an excess of organic peroxide has been claimed to liberate free acetylacetone. ${ }^{29}$ Free acetylacetone in $\mathrm{CH}_{2} \mathrm{Cl}_{2}$ absorbs at $273 \mathrm{~cm}^{-1}$, but IR, as well as NMR spectroscopic studies showed no sign of free acetylacetone, under the present reaction conditions. Furthermore, a careful measurement of the UV absorption spectrum of the reaction product of 5 with TBHP showed that the absorbance was not strong enough to originate from free acetylacetone, indicating that the absorbance was due to a vanadium(V) complex, rather than liberated acetylacetone. These results indicate that, unless acetylacetone decomposes, it is still coordinated to the vanadium atom, after the oxidation has taken place.

The kinetic results are consistent with the following two-step activation process of OV(IV)(acac) $)_{2}$ by TBHP (Scheme 1).

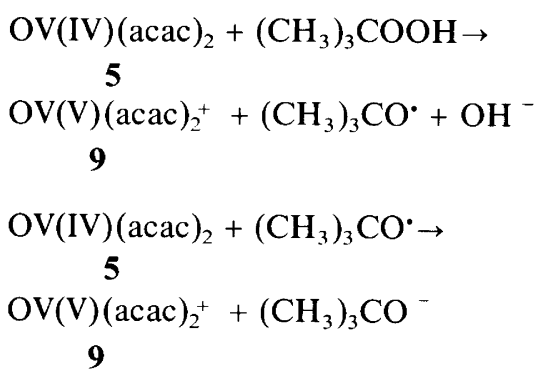

Scheme 1.

To compensate for the positive charge at the $\mathrm{OV}(\mathrm{V})(\mathrm{acac})_{2}$ complex, 9, an anion such as hydroxide, or tert-butoxide, might be attached to the vanadium atom. A dimeric vanadium complex such as $(\mathrm{acac})_{2}(\mathrm{O}) \mathrm{V}-\mathrm{O}-$ $\mathrm{V}(\mathrm{O})(\mathrm{acac})_{2}, 10$, might also be a possibility for the intermediate, but our experiments did not give any conclusive answers to this.

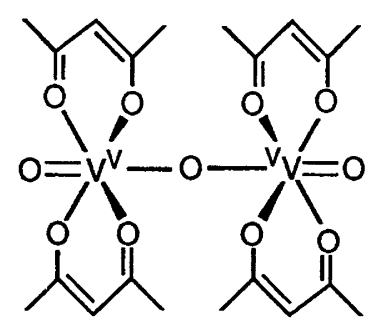

10

To find out whether $\mathrm{OV}(\mathrm{IV})(\text { acac })_{2}$ was oxidised by TBHP via an outer-sphere or inner-sphere ET pathway, the reaction was compared with the reaction between ferrocene, $\mathrm{FeCp}_{2}$, and TBHP. As the oxidation potential of $\mathrm{FeCp}_{2}$ is approximately $300 \mathrm{mV}$ lower than that of $\mathrm{OV}(\mathrm{IV})(\mathrm{acac})_{2}$ eqn. (5) should thus be more favourable than eqn. (6).

$$
\begin{aligned}
& \mathrm{Fe}(\mathrm{Cp})_{2}+\left(\mathrm{CH}_{3}\right)_{3} \mathrm{COOH} \stackrel{\mathrm{ET}}{\longrightarrow} \\
& \mathrm{Fe}(\mathrm{Cp})_{2}^{+}+\left(\mathrm{CH}_{3}\right)_{3} \mathrm{CO}^{-}+\mathrm{OH}^{-}
\end{aligned}
$$

$\mathrm{OV}(\mathrm{IV})(\mathrm{acac})_{2}+\left(\mathrm{CH}_{3}\right)_{3} \mathrm{COOH} \stackrel{\mathrm{ET}}{\longrightarrow}$

Our experiments showed, that $\mathrm{FeCp}_{2}$ and TBHP did not react within the period of time necessary for complete reaction between $\mathrm{OV}(\mathrm{IV})(\mathrm{acac})_{2}$ and TBHP, rendering an outer-sphere ET oxidation pathway for the latter reaction unlikely. The reaction of 5 with TBHP probably produces first a $\mathrm{OV}(\mathrm{V})(\mathrm{acac})_{2}$ complex. The kinetics of the oxidation of $\mathrm{VO}^{2+}$ using $\mathrm{TBHP}^{30}$ or hydrogen peroxide ${ }^{31}$ in aqueous media has received some attention and the mechanistic proposals derived from these studies are very similar to the one presented here. Furthermore, it should 
also be noted that the kinetic investigations by Espenson et al. of the reaction of unligated $\mathrm{VO}^{2+}$ with alkyl hydroperoxides in acidic aqueous medium revealed that a weak equilibrium exists between vanadium(IV) and the hydroperoxide. ${ }^{30}$ The vanadium(IV) peroxide complex is present in a steady-state concentration and the ET step is the rate-determining step. ${ }^{30}$

In an attempt to find out whether the $\mathrm{OV}(\mathrm{V})(\mathrm{acac})_{2}$ complex is an oxygen-transfer reagent, the following experiments were carried out. The oxidation of $\mathrm{OV}(\mathrm{IV})(\mathrm{acac})_{2}$ complex with TBHP was monitored by EPR spectroscopy. After the total disappearance of the V(IV) EPR signal, $\mathrm{Ph}_{3} \mathrm{P}$ or ( $Z$ )-stilbene was added to the solution in order to investigate whether an EPR signal would emerge, thus showing that a V(IV) species had been generated. However, no EPR signals were observed. In addition to the possibility of a V(V)-V(IV) cycle during the oxygen-transfer reaction, a V(V)-V(III) cycle might also be possible as both of these vanadium complexes are EPR silent. However, no epoxide was produced when $(Z)$-stilbene was added to the $\mathrm{OV}(\mathrm{V})(\mathrm{acac})_{2}$ complex, eqn. (7), showing that the oxygen transfer from the $\mathrm{OV}(\mathrm{V})(\mathrm{acac})_{2}$ complex to alkenes such as $(Z)$-stilbene is an unlikely process.

$$
\left.\mathrm{L}_{n} \stackrel{\mathrm{O}}{\mathrm{V}}(\mathrm{V})+=-H L^{\mathrm{O}}\right\rfloor+\mathrm{L}_{n} \mathrm{~V}(\mathrm{III})
$$

Vanadium(V) complexes have recently been prepared by the reaction of vanadium(III) complexes with epoxides by oxygen-atom abstraction producing an alkene and a vanadium(V) complex, eqn. (8). ${ }^{32}$

$$
\stackrel{\mathrm{O}}{\stackrel{\mathrm{O}}{\|}}+\mathrm{L}_{n} \mathrm{~V}(\mathrm{III}) \longrightarrow \mathrm{L}_{n} \mathrm{~V}(\mathrm{~V})+=
$$

Since the V(V)-V(III) cycle is in principle the reverse reaction it seems unlikely that the initially formed vana$\operatorname{dium}(\mathrm{V})$ complex would be able to epoxidise an alkene.
Furthermore, we have found that the electrochemical reduction of 5 to a vanadium(III) complex was an irreversible process and that the vanadium(III) complex formed did not exist long enough to be oxidised back to a vanadium(IV) complex, even at a scan rate of $100 \mathrm{~V} \mathrm{~s}^{-1}$.

The oxygen-transfer properties of the $\mathrm{OV}(\mathrm{V})(\mathrm{acac})_{2}$ complex is very dependent of the oxygen atom acceptor, as it was observed that replacing $(Z)$-stilbene with $\mathrm{PPh}_{3}$ led to the formation of $\mathrm{OPPh}_{3}$ by reaction with the $\mathrm{OV}(\mathrm{V})(\mathrm{acac})_{2}$ complex. This oxygen transfer from $\mathrm{V}(\mathrm{V})$ to $\mathrm{PPh}_{3}$ has also been observed for other $\mathrm{V}(\mathrm{V})$ complexes. ${ }^{33}$

In relation to the present formation of the $\mathrm{OV}(\mathrm{V})(\mathrm{acac})_{2}$ complex it should be noted that recent investigations by Zamaraev et al. using ${ }^{1} \mathrm{H}$ NMR and ${ }^{51} \mathrm{~V}$ NMR spectroscopy showed the formation of an $\mathrm{OV}(\mathrm{V})(\mathrm{acac})_{2}\left(\mathrm{OOC}\left(\mathrm{CH}_{3}\right)_{3}\right) \quad$ complex when $\mathrm{OV}(\mathrm{IV})(\mathrm{acac})_{2}$ was treated with an excess of TBHP. ${ }^{34,35}$ The formation of this complex might originate from the reaction of $\mathrm{OV}(\mathrm{V})(\mathrm{acac})_{2}-\mathrm{X}$ with $\mathrm{TBHP}$ as outlined in eqn. (9).

$$
\begin{aligned}
& 2 \mathrm{OV}(\mathrm{IV})(\mathrm{acac})_{2}+\left(\mathrm{CH}_{3}\right)_{3} \mathrm{COOH} \rightarrow \\
& 5
\end{aligned}
$$

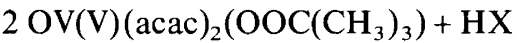

However, the $\mathrm{OV}(\mathrm{V})(\mathrm{acac})_{2}\left(\mathrm{OOC}\left(\mathrm{CH}_{3}\right)_{3}\right)$ complex decomposes within few minutes and therefore this complex cannot be the active epoxidation species throughout the entire epoxidation process. ${ }^{34,35}$ It has been suggested that a vanadium peroxide complex is responsible for the oxidation of organic compounds when TBHP is used as the terminal oxidant and $\mathrm{OV}(\mathrm{IV})(\mathrm{acac})_{2}$ is applied as the catalyst precursor. ${ }^{34,35}$

II. The electronic nature of the oxygen atom transferred by the vanadium $(V)$ complex. To investigate the electronic nature of the oxygen atom transferred from TBHP via the vanadium $(\mathrm{V})$ catalyst to the substrate, the oxidation of<smiles>O=S1c2ccccc2Sc2ccccc21</smiles>

11<smiles>O=S1(=O)c2ccccc2Sc2ccccc21</smiles>

$\mathrm{SSO}_{2}$

12<smiles>CCO[C@@H](O)C[C@H](CO)OCC</smiles><smiles>O=S1c2ccccc2S(=O)c2ccccc21</smiles>

soso

Scheme 2. 
thianthrene 5-oxide (SSO), 11, was investigated. Compound 11 has two functional groups that can be oxidised, the sulfide and the sulfoxide moiety. Nucleophilic oxidising reagents tend to oxidise the sulfoxide functionality giving $12\left(\mathrm{SSO}_{2}\right)$, while electrophilic oxidising reagents mainly oxidise the sulfide functionality leading to 13 (SOSO) (Scheme 2). ${ }^{36,37}$

Adam has introduced the parameter $X_{\text {SO }}$ defined as the $\mathrm{SSO}_{2}$ fraction of the total amount of oxidation products according to eqn. (10). ${ }^{36,37}$

$X_{\mathrm{SO}}=\frac{n_{\mathrm{SSO}_{2}}}{n_{\mathrm{SSO}_{2}}+n_{\mathrm{SOSO}}}$

An $X_{\text {so }}$ value of 0 , indicates an exclusively electrophilic oxidation, while an $X_{\text {So }}$ value of 1 is a nucleophilic oxidation. The $X_{\mathrm{SO}}$ value can thus be used to evaluate the electronic properties of the oxygen atom which is transferred from the vanadium(V) complex. The $X_{\text {so }}$ values were measured for the oxygen atom which was transferred by the oxidised states of 5, 7 and 8 using TBHP as the terminal oxidant. The following $X_{\mathrm{SO}}$ values were obtained: 5, 0.12: 7, 0.11 and $8,0.11$. These values indicated that the oxygen atom transferred from the three catalytic systems are electronically alike, however, it turns out that even though oxidations with $\mathbf{5}$ or $\mathbf{7}$ as catalyst precursors were almost complete within $2.5 \mathrm{~h}$, oxidations using 8 as a catalyst precursor did not result in any detectable oxidised product within this time interval.

If an alkylperoxovanadium(V) complex is the active oxidative intermediate, the tert-butylperoxo ligand may be mono- or bi-dentate coordinated to the metal and placed cis or trans relative to the oxo functionality. Only one vanadyl-alkylperoxo complex has been isolated and characterised and this showed a bidentate coordinated tert-butylperoxo ligand arranged cis to the oxo ligand. ${ }^{16} \mathrm{~A}$ series of attempts were made to investigate the structure of the coordination of the tert-butylperoxo group (cis or trans relative to the oxo functionality) to the $\mathrm{OV}(\mathrm{V})(\mathrm{acac})_{2}$ complex using molecular mechanics $(\mathrm{MM} 2)^{38}$ and $\mathrm{ZINDO}^{24-27}$ calculations, but no satisfactory results were obtained as the calculated energies for several possible geometrical isomers were within $0.5 \mathrm{eV}$.

III. Epoxidation of alkenes and 1,3-dienes. The oxygen transfer from the reactive vanadium(V)-alkyl peroxide complex intermediate to an alkene and a 1,3-diene was
Table 1. The cis-stilbene oxide: trans-stilbene oxide ratio as a function of time using $\mathbf{5}$ and $\mathbf{7}$ as catalysts, TBHP as the terminal oxidant and (Z)-stilbene as the substrate.

\begin{tabular}{llllllllll}
\hline & \multicolumn{3}{c}{5} & & \multicolumn{3}{c}{7} \\
\cline { 2 - 4 } \cline { 5 - 8 } & $2 \mathrm{~h}$ & $4 \mathrm{~h}$ & $7 \mathrm{~h}$ & & $2 \mathrm{~h}$ & $4 \mathrm{~h}$ & $7 \mathrm{~h}$ \\
\hline $\begin{array}{l}\text { cis-stilbene oxide: } \\
\text { trans-stilbene oxide }\end{array}$ & 0.94 & 0.83 & 0.85 & & 1.02 & 1.00 & 0.85 \\
\hline
\end{tabular}

studied. In order to study the outcome of the oxygentransfer step to the alkene, cis-alkenes were used as the substrate, as the stereochemistry of the epoxide might give information about the oxygen-transfer mechanism. The catalytic properties of $\mathbf{5}$ and $\mathbf{7}$ were very similar, as about $20 \%$ of the epoxide was produced after $2 \mathrm{~h}$ at $50{ }^{\circ} \mathrm{C}$, whereas the catalytic properties of 8 were imperceptible, as less that $1 \%$ epoxide was formed after $2 \mathrm{~h}$. In the case where 5 and 7 were used as catalyst precursors the cis-stilbene oxide and trans-stilbene oxide were formed in nearly equal amounts. The cis-stilbene oxide: trans-stilbene oxide ratio as a function of time is presented in Table 1 using 5 or $\mathbf{7}$ as the catalyst precursor. TBHP as the terminal oxidant and $(Z)$-stilbene as the substrate.

It appears from Table 1 that the cis-stilbene oxide: trans-stilbene oxide ratio was very similar for the two catalysts 5 and 7. Surprisingly the cis-stilbene oxide:transstilbene oxide ratio was not constant with time as this ratio decreased at longer reaction times. Furthermore, it was found that among the by-products of the epoxidation reaction of $(Z)$-stilbene using 5 as the catalyst and TBHP were $(E)$-stilbene and benzaldehyde. It should be noted that under the present reaction conditions, $(Z)$-stilbene did not rearrange in the presence of 5 or TBHP. Nor was cis-stilbene oxide found to rearrange in the presence of $\mathbf{5}$, TBHP, or 5 and TBHP. The formation of $(E)$-stilbene indicated that the oxygen-transfer step might be reversible. This would, according to our knowledge, be the first known example of reversibility in the oxygen-transfer step in transition-metal-catalysed epoxidations. The proposed mechanism is outlined in Scheme 3 . It should also be noted that $(E)$-stilbene was epoxidised exclusively to trans-stilbene oxide under the same reaction conditions. The conversion of $(Z)$-stilbene into $(E)$-stilbene accounts thus for the observed decrease in the cis-stilbene oxide to trans-stilbene oxide ratio.

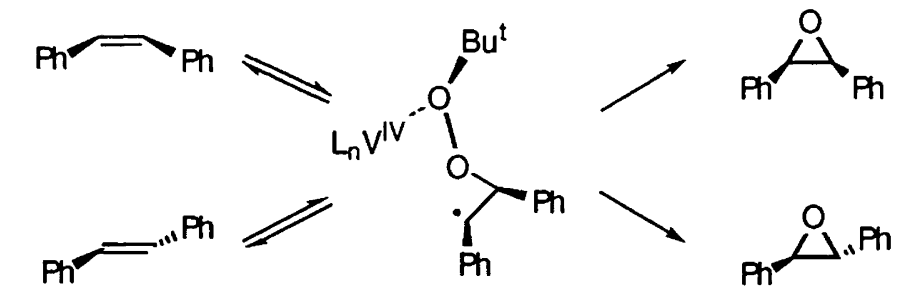

Scheme 3. 
It should be noted that the formation of a mixture of cis- and trans epoxides has also been observed in the stoicheiometric epoxidation of 2-butene using 14 as the oxidising agent, as well as other vanadium-catalysed epoxidation reactions. ${ }^{13,17}$

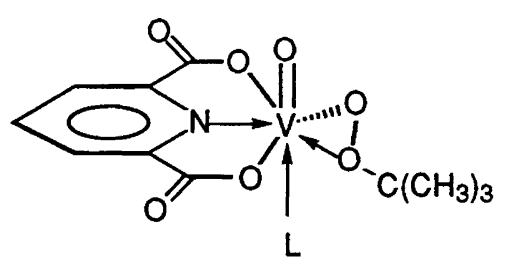

14

To investigate the possibility of a 1,4-addition of an oxygen atom to a 1,3-diene forming 2,5-dihydrofuran, we studied the possible formation of 2,5-dihydrofuran from 1,3-dienes using $\mathbf{5}$ and $\mathbf{8}$ as catalysts, but no direct oxygen transfer reaction took place under a variety of different reaction conditions. In the case of $(E, E)$-1,4-diphenyl1,3-butadiene as substrate, 5 as the catalyst and TBHP as the terminal oxidant, neither 2,5-dihydrofurans nor epoxides were formed. However, a polymerisation reaction of $(E, E)$-1,4-diphenyl-1,3-butadiene seemed to occur under these reaction conditions. If PhIO was used as the terminal oxidising agent, a mixture of $(1 E)$-trans-1,4diphenyl-3,4-epoxy-1-butene and (Z)-trans-1,4-diphenyl3,4-epoxy-1-butene was produced as well as some overoxidation products, but no 2,5-dihydrofuran could be detected. These results show that the discrete catalytic vanadium system is different from the VPS contrasting the case of discrete silver complexes showing reactivity similar to that of silver surfaces.

$I V$. Summary. The present results show that the oxidation of a series of oxovanadium(IV) complexes to the oxovanadium(V) complexes is very dependent on the organic ligands attached to the metal. The complexes with diketonato ligands are easily oxidised compared with the system with a porphyrin ligand attached to the vanadyl group. This difference can be accounted for by a lower energy of the $d^{1}$ electron in the vanadyl porphyrin system compared with the other systems. The kinetics of the oxidation of $\mathrm{OV}(\mathrm{IV})(\mathrm{acac})_{2}$ to a OV(V)( acac $)_{2}$ complex by TBHP has been studied using EPR and UV spectroscopy. Both data sets were consistent with a two-step mechanism where a hydroxide ion and a tert-butyloxyl radical are formed in the first step by ET from $\mathrm{OV}(\mathrm{IV})(\mathrm{acac})_{2}$ to TBHP. In the second step the tertbutyloxyl radical is proposed to be reduced via an ET from $\mathrm{OV}(\mathrm{IV})(\mathrm{acac})_{2}$ giving a OV(V)(acac) $)_{2}$ complex and tert-butyloxide. These reactions probably take place via inner-sphere ET reactions. The $\mathrm{OV}(\mathrm{V})(\mathrm{acac})_{2}$ complex formed is not able to epoxidise (Z)-stilbene, but $\mathrm{PPh}_{3}$ is oxidised to $\mathrm{OPPh}_{3}$. During the oxygen-transfer reactions no vanadium radicals could be detected. Based on thi- anthrene 5-oxide as a probe for the electronic nature of the oxygen atom transferred from the oxovanadium(V) complex with TBHP as the terminal oxidant, it was found that the oxygen atom transferred has electrophilic character. The oxygen atom transferred is apparently of a radical nature as a mixture of cis- and trans-epoxides are formed by epoxidation of $(Z)$-stilbene. The cis epoxide:trans epoxide ratio decreases as a function of time, and furthermore, $(E)$-stilbene is observed in the epoxidation of $(Z)$-stilbene catalysed by the vanadium complex, showing that the oxygen-transfer step might be a reversible process. The oxidation of 1,3-dienes with discrete vanadium complexes using different terminal oxidants shows no similarities to the oxidation of 1,3-butadiene on a VPS.

\section{Experimental}

${ }^{1} \mathrm{H}$ and ${ }^{13} \mathrm{C}$ NMR spectra were recorded on a Varian 300 $\mathrm{MHz}$ Gemini spectrometer. $\mathrm{CDCl}_{3}$ was used as the solvent and reported $\delta$ values are relative to tetramethylsilane (TMS). EPR spectra were recorded on a Bruker ER 200 spectrometer with a modulation frequency at $25 \mathrm{kHz}$ and an amplitude of about $100 \mathrm{mG}$. IR solution spectra were recorded on a Bruker IFS $113 \mathrm{~V}$ spectrometer and UV spectra on a Uvicon Kontron 860 spectrometer.

Materials. OV(IV)(acac) $)_{2}$ OV(IV)(tpp) and TBHP are commercially available. OV(IV)(acac) ${ }_{2}$ was recrystallised from $\mathrm{CH}_{2} \mathrm{Cl}_{2}$ before use. OV(IV)(camp) ${ }_{2}{ }^{23}$ thianthrene 5 -oxide ${ }^{39}$ and $\mathrm{PhIO}^{40,41}$ were prepared according to the literature. All other chemicals were used as received. TBHP was used as a $\mathrm{Cl}\left(\mathrm{CH}_{2}\right)_{2} \mathrm{Cl}$ solution prepared according to literature procedures. ${ }^{20}$

EPR spectra. The spectra of $\mathrm{OV}(\mathrm{IV})(\mathrm{acac})_{2}, \mathrm{OV}(\mathrm{IV})-$ $(\mathrm{camp})_{2}$ and $\mathrm{OV}(\mathrm{IV})(\mathrm{tpp})$ were recorded at a centre field value of $3315.55 \mathrm{G}$ and a $1000 \mathrm{G}$ sweep width.

EPR kinetics. The reactions were carried out in sample cells at ambient temperature in $\mathrm{Cl}\left(\mathrm{CH}_{2}\right)_{2} \mathrm{Cl}$. [OV(IV) $\left.(\mathrm{acac})_{2}\right]=0.67 \mathrm{mM}$ and $[$ TBHP] $=0.33 \mathrm{mM}$. The intensity of the more intense centre line was measured as a function of time. A second-order model proved to be the most appropriate description of the reaction.

EPR measurements in the presence of $\mathrm{PPh}_{3}$ and $(\mathrm{Z})$-stilbene. These experiments were carried out under the same conditions as for the EPR kinetic experiments. After total oxidation of $\mathrm{OV}(\mathrm{IV})(\mathrm{acac})_{2}$ to a vanadium(V) complex, $\mathrm{PPh}_{3}$ or $(Z)$-stilbene was added to the reaction mixture to investigate whether an EPR signal originating from a vanadium(IV) complex would emerge.

A parallel experiment was conducted in order to investigate the possible formation of $\mathrm{OPPh}_{3}$ or cis-stilbene oxide. Under an $\mathrm{N}_{2}$ atmosphere at $\mathrm{rt}$ slow addition of $0.05 \mathrm{mmol}$ TBHP in $2 \mathrm{ml} \mathrm{DCE}$ to a DCE solution of 5 $(0.1 \mathrm{mmol}$ in $3 \mathrm{ml})$ resulted in the formation of a vana- 
$\operatorname{dium}(\mathrm{V})$ complex as evidenced by UV spectroscopy. It should be noted that this oxidation was not complete, presumably due to metal-catalysed decomposition of the TBHP. The oxidation of OV(IV)(acac) $)_{2}$ is accompanied by a change in colour from greenish blue to brownish. When $\mathrm{PPh}_{3}$ was added to the solution, the colour returned to greenish blue. The formation of $\mathrm{OPPh}_{3}$ is evidenced by ${ }^{1} \mathrm{H}$ NMR spectroscopy $\left(\mathrm{CDCl}_{3}\right.$, TMS as internal ref.) showing two multiplets between $7.4 \mathrm{ppm}$ and $7.8 \mathrm{ppm}$. Addition of $(Z)$-stilbene to the solution containing the vanadium(V) complex does not result in a change in colour, even when the mixture was left at $60^{\circ} \mathrm{C}$ overnight. No epoxide could be detected using ${ }^{1} \mathrm{H}$ NMR spectroscopy $\left(\mathrm{CDCl}_{3}\right.$, TMS as internal ref.).

Reactions followed by UV spectroscopy. $\mathrm{OV}(\mathrm{IV})(\mathrm{acac})_{2}$ $(0.16 \mathrm{mM})$ and TBHP $(0.16 \mathrm{mM})$ in $\mathrm{Cl}\left(\mathrm{CH}_{2}\right)_{2} \mathrm{Cl}$ were mixed at $\mathrm{rt}$ and spectra were recorded from $240 \mathrm{~nm}$ to $340 \mathrm{~nm}$ every $24 \mathrm{~s}$.

Kinetic studies by UV spectroscopy. The reaction was studied at $\mathrm{rt}$ at $300 \mathrm{~nm}$ with the following concentrations: $\left[\mathrm{OV}(\mathrm{IV})(\mathrm{acac})_{2}\right]=0.067 \mathrm{mM}$ and $[$ TBHP $]=0.033 \mathrm{mM}$ in $\mathrm{Cl}\left(\mathrm{CH}_{2}\right)_{2} \mathrm{Cl}$.

IR spectra. For these experiments the [OV(IV) $\left.(\mathrm{acac})_{2}\right]=0.045 \mathrm{M}$, while various concentrations of TBHP were applied. The spectra were recorded in the $600-4000 \mathrm{~cm}^{-1}$ region.

Stability of $\mathrm{OV}(\mathrm{IV})(\mathrm{acac})_{2}$ under various reaction conditions. 2,4-Pentanedione has a very characteristic ${ }^{1} \mathrm{H}$ NMR signal at $\delta 15.4$ (enol form), which can be easily detected if it is liberated during the oxidation of $\left[\mathrm{OV}(\mathrm{IV})(\mathrm{acac})_{2}\right]$. This signal was not observed during the stoichiometric reactions.

Electrochemical measurements. The measurements were conducted for a $2 \mathrm{mM}$ DMF solution of $\mathrm{OV}(\mathrm{IV})(\mathrm{acac})_{2}$ containing $0.1 \mathrm{M} \mathrm{TBABF}_{4}$ with a Pt working electrode. The reference electrode was $\mathrm{Ag} / \mathrm{AgI}$ with anthraquinone as an internal standard $\left(E^{\circ}=-400 \mathrm{mV}\right)$.

Procedure for the oxidation of thianthrene 5-oxide. $1.25 \mathrm{mmol}$ of thianthrene 5-oxide and $4.5 \mu \mathrm{mol}$ of $\mathrm{OV}(\mathrm{IV})(\mathrm{acac})_{2}$ were dissolved in $10 \mathrm{ml} \mathrm{Cl}\left(\mathrm{CH}_{2}\right)_{2} \mathrm{Cl}$, degassed with $\mathrm{N}_{2}$ and heated to $50^{\circ} \mathrm{C}$. $0.124 \mathrm{mmol}$ of TBHP were added at this temperature. Aliquots were drawn at various time intervals within the first $8 \mathrm{~h}$ of reaction time and the distribution of the products was investigated by HPLC using 2-nitroaniline as an external standard. The $X_{\text {SO }}$ values are an average of five measurements for 5 and $\mathbf{7}$. Longer reaction times were necessary to obtain the $X_{\text {SO }}$ value for $\mathbf{8}$ which is based on two aliquots.

Procedure for the epoxidation of alkenes and 1,3-dienes. $0.5 \mathrm{mmol}$ of the appropriate alkene/diene was dissolved in $\mathrm{Cl}\left(\mathrm{CH}_{2}\right)_{2} \mathrm{Cl}$ and $0.025 \mathrm{mmol}$ of the catalyst and $1.0 \mathrm{mmol}$ of TBHP were added, after which the reaction mixture was heated to $50^{\circ} \mathrm{C}$. Aliquots were withdrawn at various time intervals, the reaction mixture was filtered through Celite and the solvent evaporated off. The reaction mixture was analysed by ${ }^{1} \mathrm{H}$ NMR spectroscopy. ${ }^{1} \mathrm{H}$ NMR spectra $\left(300 \mathrm{MHz}, \mathrm{CDCl}_{3}\right.$ ) of cis-stilbene oxide: $\delta$ $4.37(\mathrm{~s}, 2 \mathrm{H}), 7.17(\mathrm{~m}, 10 \mathrm{H})$; trans-stilbene oxide: $\delta 3.87$ (s, $2 \mathrm{H}), 7.36(\mathrm{~m}, 10 \mathrm{H})$.

Procedure for rearrangement experiments $1 \mathrm{mmol}$ of $(Z)$ stilbene in $\mathrm{Cl}\left(\mathrm{CH}_{2}\right)_{2} \mathrm{Cl}$ was heated to $80^{\circ} \mathrm{C}$ for $3 \mathrm{~h}$ in the presence of $\mathrm{OV}(\mathrm{IV})(\mathrm{acac})_{2}$ (5) $(0.04 \mathrm{mmol})$. No transalkene could be detected. $0.076 \mathrm{mmol}$ cis-stilbene oxide was heated to $70^{\circ} \mathrm{C}$ in the presence of (a) $0.04 \mathrm{mmol}$ $\mathrm{OV}(\mathrm{IV})(\mathrm{acac})_{2}$, (b) $0.12 \mathrm{mmol}$ TBHP and (c) $0.04 \mathrm{mmol}$ $\mathrm{OV}(\mathrm{IV})(\mathrm{acac})_{2}$ and $0.12 \mathrm{mmol}$ TBHP. The ${ }^{1} \mathrm{H}$ NMR spectrum taken after $20 \mathrm{~h}$ showed no trans-stilbene oxide. Other products, mainly overoxidized, did, however, appear.

Acknowledgements. Thanks are expressed to Marianne Kaaber, Martin Bech and Jens Arne Pedersen for valuable aid with the EPR experiments. We are also indebted to Niels T. Kjær and Henning Lund for carrying out the electrochemical experiments.

\section{References}

1. Rehder, D. Angew. Chem., Int. Ed. Engl. 30 (1991) 148.

2. Butler, A. and Walker, J. V. Chem. Rev. 93 (1993) 1937.

3. Clague, M. J., Keder, N. L. and Butler, A. Inorg. Chem. 32 (1993) 4754.

4. Centi, G. Vanadyl Pyrophosphate Catalysts, Elsevier, Amsterdam 1993.

5. Campbell, I. M. Catalysis at Surfaces, Chapman and Hall, New York, 1988

6. Centi, G., Trifirò, F., Ebner, J. R. and Franchetti, V. M. Chem. Rev. 88 (1988) 55.

7. Schiøtt, B., Jørgensen, K. A. and Hoffmann, R. J. Phys. Chem. 95 (1991) 2297.

8. Schiøtt, B. and Jørgensen, K. A. In: Centi, G., Ed., Catalysis Today; Elsevier, Amsterdam 1993, p. 79.

9. Gould, E. S., Hiatt, R. R. and Irwin, K. C. J. Am. Chem. Soc. 90 (1968) 4573.

10. Indictor, N. and Brill, W. F. J. Org. Chem. 30 (1965) 2074.

11. Laszlo, P., Levart, M. and Singh, G. P. Tetrahedron Lett. 32 (1991) 3167.

12. Sheldon, R. A. and Kochi, J. A. Metal-Catalyzed Oxidations of Organic Compounds, Academic Press, New York 1981.

13. Jørgensen, K. A. Chem. Rev. 89 (1989) 431.

14. Sawaki, Y. In: Patai, S., Ed., The chemistry of Hydroxyl, Ether and Peroxide Groups, Wiley Interscience, Chichester 1993, p. 587.

15. Bonchio, M., Conte, V., Furia, F. D. and Modena, G. $J$. Org. Chem. 54 (1989) 4368.

16. Mimoun, H., Chaumette, P., Mignard, M. and Saussine, L. New J. Chem. 7 (1983) 467.

17. Mimoun, H., Saussine, L., Daire, E., Postel, M., Fischer, J. and Weiss, R. J. Am. Chem. Soc. 105 (1983) 3101.

18. Butler, A., Clague, M. J. and Meister, G. E. Chem. Rev. 94 (1994) 625. 
19. Colpas, G. J., Hamstra, B. J., Kampf, J. W. and Pecoraro, V. L. J. Am. Chem. Soc. 116 (1994) 3627.

20. Sharpless, K. B. and Verhoeven, T. R. Aldrichim. Acta 12 (1979) 201.

21. Roberts, J. T., Capote, A. J. and Madix, R. J. Surf. Sci. 253 (1991) 13.

22. Schiøtt, B. and Jørgensen, K. A. J. Phys. Chem. 97 (1993) 10737.

23. Togni, A. Organometallics 9 (1990) 3106.

24. Pople, J. A., Beveridge, D. L. and Dobosh, P. A. J. Chem. Phys. 47 (1967) 2026.

25. Ridley, J. and Zerner, M. Theor. Chim. Acta (Berlin) 32 (1973) 111.

26. Zerner, M. C., Loew, G. H., Kirchner, R. F. and MuellerWesthoff, U. T. J. Am. Chem. Soc. 102 (1980) 589.

27. Anderson, W. P., Cundari, T. R., Drago, R. S. and Zerner, M. C. Inorg. Chem. 29 (1990) 1.

28. Vonchio, M., Conte, V., Furia, F. D., Modena, G., Moro, S., Carofiglio, T., Magno, E. and Pastore, P. Inorg. Chem. 32 (1993) 5797.

29. Svitych, R. B., Buchachenko, A. L., Yablonskii, O. P., Rzhevskaya, N. N., Belyaev, V. A. and Petukhov, A. A. Kinetics and Catalysis (1976) 60.

30. Ma, R., Bakac, A. and Espenson, J. H. Inorg. Chem. 31 (1992) 1925.
31. Funahashi, S., Funada, S., Inamo, M., Kurita, R. and Tanaka, M. Inorg. Chem. 21 (1982) 2202.

32. Vivanco, M., Ruiz, J., Floriani, C., Chiesi-Villa, A. and Rizzoli, C. Organometallics 12 (1993) 1802.

33. Zhang, Y. and Holm, R. H. Inorg. Chem. 29 (1990) 911.

34. Talsi, E. P., Chinakov, V. D., Babenko, V. P. and Zamaraev, K. I. J. Mol. Catal. 81 (1993) 235.

35. Zamaraev, K. J. Mol. Catal. 81 (1993) 275.

36. Adam, W., Haas, W. and Lohray, B. B. J. Am. Chem. Soc. $113(1991) 6202$.

37. Adam, W. and Golsch, D. Chem. Ber. 127 (1994) 1111.

38. Burkert, U. and Allinger, N. L. Molecular Mechanics, Am. Chem. Soc., Washington DC 1982.

39. Ballistreri, F. P., Tomaselli, G. A., Toscano, R. M., Conte, V. and Furia, F. D. J. Am. Chem. Soc. 113 (1991) 6209.

40. Saltzman, H. and Shaefin, J. G. In: Baumgarten H. E., Ed., Organic Synthesis, Coll. Vol. V; Wiley, New York 1973, p. 658.

41. Nappa, M. J. and Tolman, C. A. Inorg. Chem. 24 (1985) 4711.

Received February 15, 1995. 